AIR WAR COLLEGE

AIR UNIVERSITY

DMHRSwhy?

\title{
THE VALUE OF THE DEFENSE MEDICAL HUMAN RESOURCE SYSTEM-INTERNET (DMHRSi) TO THE MILITARY HEALTH SYSTEM (MHS)
}

by

Jason J. Lennen, Lieutenant Colonel, USAF, BSC

A Research Report Submitted to the Faculty

In Partial Fulfillment of the Graduation Requirements

Advisor: Colonel David Cohen

February 2015 


\section{Report Documentation Page}

Form Approved

OMB No. 0704-0188

Public reporting burden for the collection of information is estimated to average 1 hour per response, including the time for reviewing instructions, searching existing data sources, gathering and maintaining the data needed, and completing and reviewing the collection of information. Send comments regarding this burden estimate or any other aspect of this collection of information,

including suggestions for reducing this burden, to Washington Headquarters Services, Directorate for Information Operations and Reports, 1215 Jefferson Davis Highway, Suite 1204, Arlington

VA 22202-4302. Respondents should be aware that notwithstanding any other provision of law, no person shall be subject to a penalty for failing to comply with a collection of information if it

does not display a currently valid OMB control number.

\begin{tabular}{|c|c|c|}
\hline $\begin{array}{l}\text { 1. REPORT DATE } \\
\text { FEB } 2015\end{array}$ & 2. REPORT TYPE & $\begin{array}{l}\text { 3. DATES COVERED } \\
\mathbf{0 0 - 0 0 - 2 0 1 5} \text { to 00-00-2015 }\end{array}$ \\
\hline \multirow{3}{*}{\multicolumn{2}{|c|}{$\begin{array}{l}\text { 4. TITLE AND SUBTITLE } \\
\text { DMHRSwhy? The Value Of The Defense Medical Human Resource } \\
\text { System-Internet (DMHRSi) To The Military Health System (MHS) }\end{array}$}} & 5a. CONTRACT NUMBER \\
\hline & & 5b. GRANT NUMBER \\
\hline & & 5c. PROGRAM ELEMENT NUMBER \\
\hline \multirow{3}{*}{\multicolumn{2}{|c|}{ 6. AUTHOR(S) }} & 5d. PROJECT NUMBER \\
\hline & & 5e. TASK NUMBER \\
\hline & & 5f. WORK UNIT NUMBER \\
\hline \multicolumn{2}{|c|}{$\begin{array}{l}\text { 7. PERFORMING ORGANIZATION NAME(S) AND ADDRESS(ES) } \\
\text { Air War College, Air University,,Maxwell AFB,AL }\end{array}$} & $\begin{array}{l}\text { 8. PERFORMING ORGANIZATION } \\
\text { REPORT NUMBER }\end{array}$ \\
\hline \multirow{2}{*}{\multicolumn{2}{|c|}{ 9. SPONSORING/MONITORING AGENCY NAME(S) AND ADDRESS(ES) }} & 10. SPONSOR/MONITOR'S ACRONYM(S) \\
\hline & & $\begin{array}{l}\text { 11. SPONSOR/MONITOR'S REPORT } \\
\text { NUMBER(S) }\end{array}$ \\
\hline
\end{tabular}

12. DISTRIBUTION/AVAILABILITY STATEMENT

Approved for public release; distribution unlimited

13. SUPPLEMENTARY NOTES

14. ABSTRACT

The Military Health System (MHS) uses a variety of systems and processes to manage its most important asset???its people. Chief among the systems employed to do this is the Defense Medical Human Resource System-internet (DMHRSi). DMHRSi has been fully operational for more than five years now, but the overall value of this system has not been assessed. In light of ongoing fiscal challenges, a new MHS governance structure, and a strategic shift toward Joint medical operations, now is the time to ensure DMHRSi is the best value for the MHS.

15. SUBJECT TERMS

16. SECURITY CLASSIFICATION OF:

a. REPORT

unclassified b. ABSTRACT unclassified c. THIS PAGE unclassified
17. LIMITATION OF ABSTRACT

Same as Report (SAR)
18. NUMBER

OF PAGES

19a. NAME OF

RESPONSIBLE PERSON

34 


\section{DISCLAIMER}

The views expressed in this academic research paper are those of the author and do not reflect the official policy or position of the US government, the Department of Defense, or Air University. In accordance with Air Force Instruction 51-303, it is not copyrighted, but is the property of the United States government. 


\section{Biography}

Lieutenant Colonel Jason Lennen is currently a student at Air War College, Air

University, Maxwell AFB, AL. He is a licensed and board certified pharmacist who entered the U.S. Air Force in August 1998 through a direct commission as a second lieutenant. He has served at clinic, hospital, and medical center locations in a variety of student, staff, instructor, and leadership positions, and has deployed twice in support of Operations ENDURING FREEDOM and IRAQI FREEDOM. Prior to his current assignment, Colonel Lennen served as the Commander of the 92d Medical Operations Squadron, as well as the Deputy Commander of the 92d Medical Group, Fairchild AFB, WA. He holds bachelor's and doctorate degrees in pharmacy, a master's degree in business administration, and a master's degree in military operational art and science. 


\begin{abstract}
The Military Health System (MHS) uses a variety of systems and processes to manage its most important asset...its people. Chief among the systems employed to do this is the Defense Medical Human Resource System-internet (DMHRSi). DMHRSi has been fully operational for more than five years now, but the overall value of this system has not been assessed. In light of ongoing fiscal challenges, a new MHS governance structure, and a strategic shift toward Joint medical operations, now is the time to ensure DMHRSi is the best value for the MHS.

This paper provides an overview of DMHRS $i$, identifies both its benefits and costs, assesses its current value, and recommends strategies to improve its value as the MHS adapts to a changing operating environment. The benefits and costs were identified through an evaluation of MHS policies and procedures, and interviews with key personnel at medical treatment facilities, Service headquarters agencies, and the Defense Health Agency. The system's overall value was assessed through a benefit-cost analysis that used both quantitative and qualitative factors, including direct expenses, personnel time, and opportunity costs.

This paper argues that DMHRSi's value varies based on organizational level and specific capabilities employed. The author assesses that DMHRS $i$ is presently an overall good value to the MHS and provides four recommendations to improve this value going forward. First, existing DMHRSi capabilities must be utilized to a greater extent. Second, new DMHRSi capabilities should be developed. Third, existing systems with redundant capabilities should be eliminated. Finally, the costs associated with DMHRSi's labor cost assignment function must be reduced. This combination of enhanced benefits and diminished costs will maximize the value of DMHRS $i$ as the MHS moves into the future.
\end{abstract}




\section{Contents}

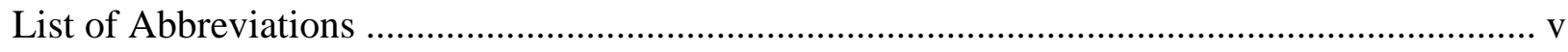

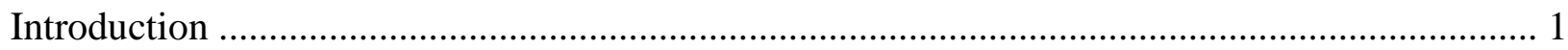

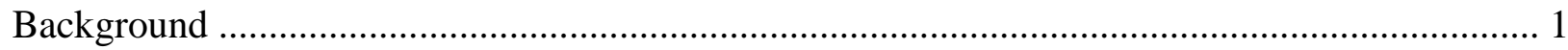

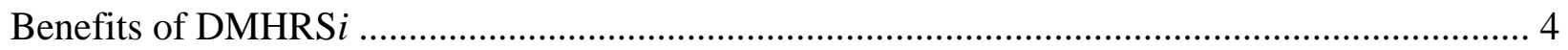

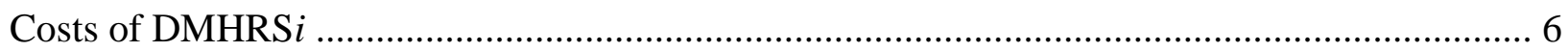

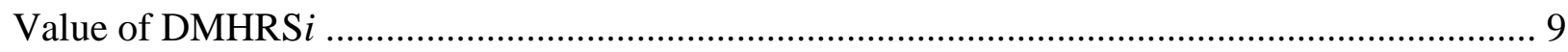

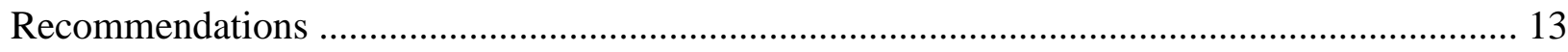

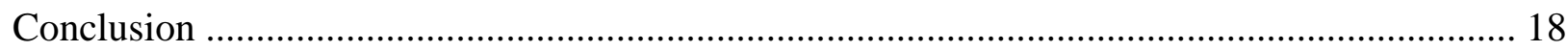

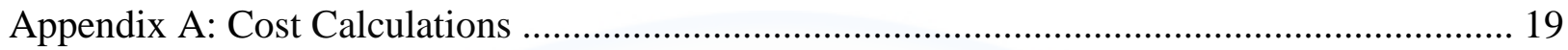

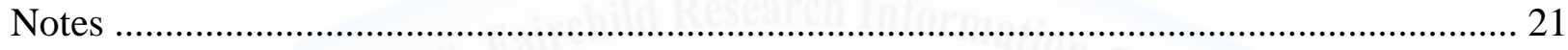

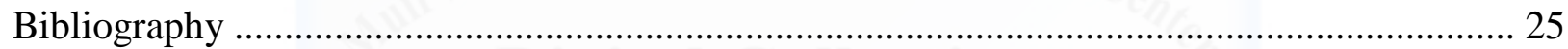




\section{List of Abbreviations}

AFMOA

AFMS

AHLTA

AMEDD

$\operatorname{ASD}(\mathrm{HA})$

ATAAPS

BUMED

CHCS

CONOPs

DHA

DMHRS $i$

DoD

E\&T

eMSM

FTE

HRM

LCA

MEPRS

MERHCF

MHS

MTF

NCR

OASD(HA)

OSD

OUSD(C)

TMA
Air Force Medical Operations Agency

Air Force Medical Service

Armed Forces Health Longitudinal Technology Application

Army Medical Department

Assistant Secretary of Defense (Health Affairs)

Automated Time Attendance and Production System

Bureau of Medical and Surgery

Composite Health Care System

concept of operations

Defense Health Agency

Defense Medical Human Resource System - internet

Department of Defense

education and training

enhanced multi-service market

full-time equivalent

human-resource management

labor cost assignment

Medical Expense and Performance Reporting System

Medicare-Eligible Retiree Health Care Fund

Military Health System

medical treatment facility

National Capital Region

Office of the Assistant Secretary of Defense (Health Affairs)

Office of the Secretary of Defense

Office of the Under Secretary of Defense (Comptroller)

TRICARE Management Activity 


\section{$\underline{\text { Introduction }}$}

The benefits, costs, and value of the Military Health System's (MHS) human-resource management (HRM) system, named the Defense Medical Human Resource System - internet (DMHRSi), are unclear. At a time when the MHS is facing significant resource reductions, changes to its governance structure, and shifting strategic direction, assessing these factors is vital to efficient and effective healthcare operations. DMHRSi's benefits have not been fully realized and its costs far exceed the $\$ 14$ million annual contract. ${ }^{1}$ With Department of Defense (DoD) missions at risk from $\$ 600$ billion in budget cuts over the next decade, and healthcare costs an increasing percentage of defense expenditures, the MHS must get the most from every dollar spent on DMHRSi. ${ }^{2}$ Furthermore, the effectiveness of increasingly Joint medical operations demands an integrated HRM system that informs decision-making at all levels.

\section{$\underline{\text { Background }}$}

HRM is vital to organizational success and delivering quality healthcare. ${ }^{3}$ The DoD and its subordinate MHS are no exception. DoD's HRM enterprise comprises diverse programs to recruit, train, manage, and retain personnel. It equips decision-makers with personnel data, including availability, location, competency, and readiness. ${ }^{4}$ DoD employs over 700 different information systems to support these vast efforts. ${ }^{5}$ The MHS operates dozens of them, including the Armed Forces Health Longitudinal Technology Application (AHLTA) and DMHRSi ${ }^{6}$ Collectively, these systems support healthcare operations and the Total Force.

DMHRS $i$ is an internet-based system used by the MHS to standardize key HRM elements across the Service medical departments (i.e., Air Force Medical Service (AFMS), Army Medical Department (AMEDD), and Navy Bureau of Medicine and Surgery (BUMED)) and the DHA. ${ }^{7}$ The system was the MHS' solution to inadequate integration, coordination, and visibility of tri- 
Service medical personnel during the Gulf War. ${ }^{8}$ It was acquired in 2006, and implemented at all 800 sites by September 2009, fulfilling the Assistant Secretary of Defense for Health Affairs (ASD(HA)) requirement for integrated and accurate MHS manpower, utilization, and expense data. ${ }^{9}$ DMHRS $i$ integrates data from 23 source systems and allows access to MHS-wide HRM information through the five modules in figure 1: manpower, personnel, labor cost assignment (LCA), education and training (E\&T), and readiness. ${ }^{10}$

The manpower module is used to manage information regarding each medical treatment facility's (MTF's) authorized positions (“spaces”). It shows decision-makers where personnel of all types (e.g., active duty, government civilian, contractor) are assigned and working. ${ }^{11}$ As a complement to the manpower module, the personnel module provides information about each MTF's assigned people (“faces"), including positions, demographics, occupation, and skill level. ${ }^{12}$ This informs leaders of the capabilities and status of who is available to accomplish the mission.

In addition to "faces" and "spaces" data, DMHRSi provides MTF personnel costs via the LCA module. ${ }^{13}$ This apprises decision-makers of how much money is spent on medical labor; an important input into the DoD-directed "uniform expense and labor reporting system" called the Medical Expense and Performance Reporting System (MEPRS). ${ }^{14}$ Unlike the other DMHRS $i$ modules, which import data, LCA data is input directly by employees through twice-monthly timecards. (Civilians report their hours in both DMHRSi and the Automated Time Attendance and Production System (ATAAPS)). The LCA module is the sole source of MHS medical labor cost data.

As depicted in figure 1, DMHRSi also contains E\&T and readiness modules. The E\&T module was designed to be a "one-stop shop" for decision-makers to assess the competency and 
Figure 1. DMHRSi Data Types

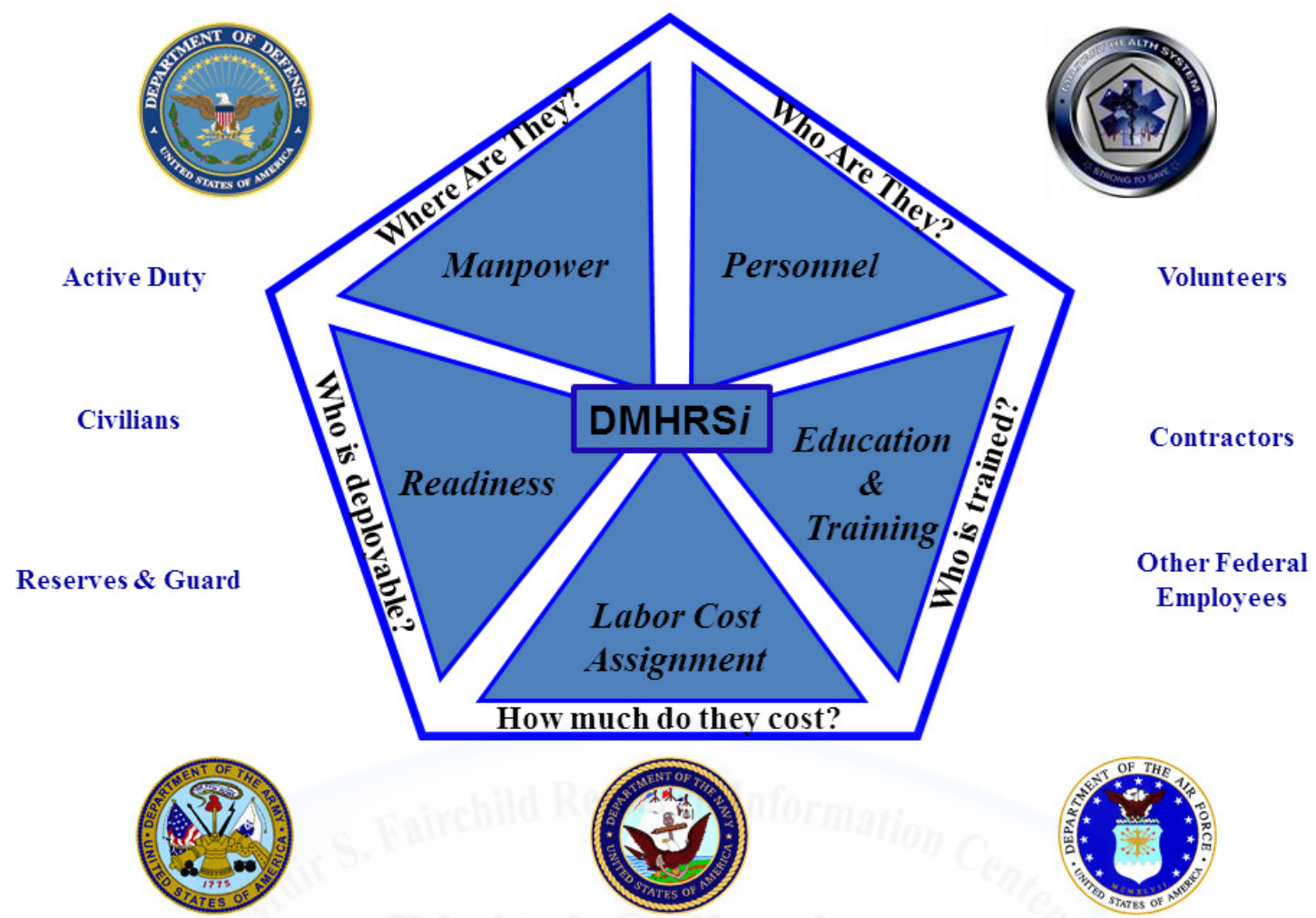

(Adapted from TRICARE Management Activity, "Human Capital Information \& The Defense Medical Human Resources System - internet (DMHRSi)," accessed 18 November 2014.)

currency of MTF personnel. ${ }^{15}$ Among other things, it provides training requirements and status, course scheduling, and electronic training records. The readiness module, on the other hand, provides visibility and management of the deployment readiness of medical personnel and equipment. Information contained within this module includes readiness posture, equipment issuance, readiness training, security clearance, and medical readiness requirements.

Collectively, the five DMHRSi modules constitute a robust HRM system for the MHS. Although each has distinct functions, the modules are linked through a master database providing comprehensive report capabilities to inform decisions at all levels. Current ASD(HA) policy mandates use of three modules (manpower, personnel, and LCA), leaving use of the others to Service discretion. ${ }^{16}$ Although BUMED is presently the only medical department using all five 
modules, a point explored later, DMHRSi benefits all Services (and the DHA).

\section{Benefits of DMHRSi}

The description above makes it clear-DMHRSi is beneficial to the MHS. This paper focuses on the system's unique benefits instead of detailing every report it produces. These benefits are primarily from the integration and visibility of HRM data, which were previously achievable only by querying multiple systems. Importantly, however, DMHRSi benefits vary based on the level of the organization using it.

At the highest MHS levels, DMHRSi provides visibility of all medical personnel, including civilians and contractors, within and across the Services—-the very reason DMHRS $i$ was acquired. This is critical to MHS management, and has gained importance with the MHS governance reform in 2013 that established the DHA and made it responsible for "shared services, functions, and activities of the MHS and other common clinical and business processes." ${ }^{17}$ DHA presently oversees 10 shared services, and DMHRSi directly supports the management of two of them: budget and resource management, and medical education and training. ${ }^{18}$ DHA is also responsible for the National Capital Region (NCR) enhanced MultiService Market (eMSM). These functions simply could not be executed using the myriad incompatible, Service-specific HRM systems. Furthermore, DMHRSi produces many MHS cost and productivity reports for the DoD, Congress, and others—expanding requirements under today's tighter budgets and stricter oversight. For example, DMHRS $i$ was recently used to answer a congressional call for MHS behavioral health staffing. ${ }^{19}$

Similarly, DMHRS $i$ supports HRM decision-making at the Service level by consolidating data from their subordinate MTFs. DMHRSi's integrated manpower and personnel information allows career field managers and other leaders to efficiently manage staffing levels and make 
resource allocation decisions across multiple MTFs. AMEDD, for example, recently started using DMHRSi to analyze "face-to-space" data to ensure compliance with changing manpower authorizations across the department. ${ }^{20}$ Previously, Army MTFs were locally tracking this information on spreadsheets and then adjusting manpower based on their budget. ${ }^{21}$ Moreover, the AFMS will soon use DMHRSi as the baseline for manpower standards, a move away from the traditional workload-based calculations. ${ }^{22}$ Additionally, the LCA module provides personnel and labor data at the individual level, unlike previous HRM systems that only reported full-time equivalents (FTEs). ${ }^{23}$ When combined with workload data, this allows headquarters staffs to assess individual and MTF productivity, and then make optimal policy and personnel management decisions. $^{24}$

Additional DMHRS $i$ benefits come from LCA data standardization across the medical departments. First, the LCA module eliminated three "antiquated, stand-alone, stove-piped systems," thereby reducing costly redundancies. ${ }^{25}$ It also introduced a standard method to calculate MEPRS labor costs and, therefore, the "level of effort" used to determine the Services' shares of the Medicare-Eligible Retiree Health Care Fund (MERHCF). ${ }^{26}$ MERHCF reimbursements are derived from MEPRS expense data and cover a significant portion of MTF direct-care expenses. ${ }^{27}$ DoD was allocated $\$ 1.9$ billion (12.5 percent of direct-care expenses) from the MERHCF in FY13, over $\$ 500$ million of which was reimbursement for medical labor costs reported through DMHRSi ${ }^{28}$ Before DMHRSi, highly variable LCA data made MERHCF calculations more prone to errors that adversely impact the Services' medical budgets. ${ }^{29}$ For example, incomplete MEPRS data cost the Army \$20 million of MERHCF funds in FY07 and the Air Force $\$ 23.5$ million in FY09. ${ }^{30}$

DMHRS $i$ is also touted to have many benefits at the MTF level, including HRM data 
consolidation, redundant system elimination, and medical training and readiness management. ${ }^{31}$ However, usage variations between MTFs result in many of these benefits not being realized. Interviews with four MTF MEPRS managers (two hospitals and two clinics) from the three Services revealed two common DMHRSi benefits: detailed reports on personnel utilization and MEPRS inputs "so we don't lose manpower or money."32 (One MEPRS manager was particularly innovative and uses DMHRSi to make efficiency comparisons to other MTFs, generate data to support manpower decisions, assess Unit Manpower Document accuracy, and identify patient safety, provider quality-of-life, and staff overwork issues. ${ }^{33}$ )

The DMHRS $i$-based LCA process is also a benefit to the MTFs, as it is easier, less timeconsuming, and arguably more accurate than previous processes. ${ }^{34}$ Labor-reporting requirements for MHS personnel have existed since the MEPRS program was established in 1985, but DMHRS $i$ was the first LCA tool to be internet-based and include customizable user templates. ${ }^{35}$ DMHRSi's consolidated data and robust reporting options have the potential to provide many other benefits at the MTF level, but there is currently no mechanism for determining the extent of utilization.

Collectively, DMHRSi's benefits are primarily related to the integration and visibility of HRM data that supports decision-making at all MHS levels. These benefits appear greatest for leaders requiring HRM data from multiple sources, as well as for those taking advantage of more of the system's non-mandated capabilities. There's little question that the MHS benefits from DMHRSi. These benefits, though, come at a cost.

\section{Costs of DMHRSi}

DMHRS $i$ has direct and indirect costs; both are essential to understanding what the MHS is paying to achieve the benefits above. Like these benefits, DMHRSi costs are spread across 
MHS levels.

DMHRSi's direct costs come from software licenses and salaries. The DMHRSi contract—software licensing and maintenance, helpdesk services, and information technology support-costs $\$ 11$ million to $\$ 14$ million each year. ${ }^{36}$ The AFMS also pays $\$ 750,000$ per year for a six-FTE DMHRS $i$ support team that trains new MEPRS managers, offers a Service-level helpdesk, and extracts DMHRSi data for analysis. BUMED spends about $\$ 375,000$ annually for a GS-14 and four GS-12s to provide similar DMHRS $i$ support to the Navy. ${ }^{37}$ Moreover, the Air Force Medical Operations Agency (AFMOA) employs a GS-12 MEPRS manager who spends one-third of his time on DMHRSi (costing about \$23,000 annually), and AMEDD employs a GS-13 fully dedicated to DMHRSi management (adding $\$ 90,000$ to direct costs). ${ }^{38}$ Most MTFs also employ a full-time MEPRS manager (usually GS-9) with most of their time dedicated to DMHRSi tasks, ${ }^{39}$ costing the MHS an additional $\$ 23.3$ million each year. ${ }^{40}$ This labor cost, ironically, is mainly for tracking labor costs.

The LCA function is also responsible for DMHRSi's highest indirect costs— the wages, lost productivity, and employee dissatisfaction associated with completing timecards. ${ }^{41}$ Timecard accuracy, often debated due to inconsistencies and poor practices like "crazy 8's" (where employees enter eight hours of labor each day without regard to actual hours worked), ${ }^{42}$ is worth mentioning. DHA recently compared FY13 DMHRSi LCA data and Composite Health Care System (CHCS) workload data, and concluded that the evaluated timecards (for providers) were 92 percent accurate. ${ }^{43}$ Accuracy estimates by MTF MEPRS managers, however, vary widely from 40 to 90 percent. $^{44}$ Although the data is imperfect, DMHRS $i$ and MEPRS manager interventions have likely increased timecard accuracy. This accuracy, of course, generates costs to all MTF employees. 
The time needed to complete an accurate DMHRSi timecard varies, but interviews for this paper (and my five years of experience) found that it takes one minute per person per duty day_roughly 10 minutes per pay period. ${ }^{45}$ Therefore, MHS personnel spend about 740,000 hours entering labor data into DMHRSi each year (costing $\$ 54.4$ million). ${ }^{46}$ Not only is this a sizable expense, but the 92,000 lost man-days is a major opportunity cost in terms of potential patient care, readiness, and other mission requirements. A physician, for example, sacrifices the equivalent of 17 patient appointments annually_a full day in clinic_-to complete timecards. Opportunity costs like these grow as timecards navigate the review process. Timekeepers are a safeguard against timecard inaccuracy, but are also an added cost. Most MTFs designate timekeepers with responsibility for reviewing and approving timecards. Timekeepers are each assigned an average of 30 people, and spend around 30 minutes performing these duties each pay period. $^{47}$ This adds 9,200 man-days and $\$ 2.7$ million to DMHRSi’s indirect costs. ${ }^{48}$ The LCA costs don't end there because, invariably, tardy timecards need further attention.

In addition to timecard accuracy, timeliness is important. The DoD MEPRS Manual states, "accurate and timely collection and processing of labor hour data is essential..." because late timecards result in incomplete MEPRS and lower MERHCF receipts. ${ }^{49}$ As a result, policy requires 100 percent timecard completion before MEPRS is submitted and MTF commanders must provide their DMHRSi status to higher headquarters monthly. ${ }^{50}$ This, in turn, drives additional resources toward ensuring compliance. The MTF MEPRS managers interviewed said that three percent of their members are delinquent on their timecards each pay period; half of these don't comply after a reminder and require follow-up by unit leaders. Projecting these rates across the MHS, around 50,000 timecards per year are addressed by squadron leadership. Again, this is a hefty opportunity cost to the MHS. 
Finally, DMHRSi's indirect costs go beyond wages and lost productivity. The system is a source of employee dissatisfaction, ranking near the bottom (\#17 of 21) of MHS data systems in percent of "users satisfied." 51 For some, there is frustration with DMHRSi's report performance. It uses a live database where report requests and system operations compete for processing, so lag times increase with larger amounts of data and numbers of users. Servicelevel program managers voiced the most displeasure with report performance—not surprising since they query large datasets and are responsible to senior leaders. ${ }^{52}$ For many though, DMHRS $i$ dissatisfaction is related to timekeeping, the only interaction most MHS employees have with it. Many see timecards as an "inconvenience" or "impediment" with few benefits, while civilians cite the need to submit timecards in two systems as a "waste of time."53 Regardless of the specific source(s) of DMHRSi dissatisfaction, it likely impacts employee morale and retention, and patient care.

In summary, DMHRSi's direct costs to the MHS approach $\$ 40$ million each year, while its indirect costs are, conservatively, an additional \$57 million and 812,000 man-hours of lost productivity. That's nearly $\$ 100$ million and 100,000 man-days, along with staff dissatisfaction, for integrated HRM data. The question then becomes... are the benefits worth the costs?

\section{$\underline{\text { Value of DMHRSi }}$}

Value, in simple terms, is benefits relative to costs-the higher this ratio, the greater the value. Value in healthcare, for example, is a combination of qualitative and quantitative measures to yield "outcomes achieved per dollar spent." ${ }^{\text {"54 }}$ The MHS "Quadruple Aim" takes this hybrid approach, defining value as the sum of readiness, quality care, and population health, divided by cost. ${ }^{55}$ Along these lines, DMHRSi's value is its quantitative and qualitative impact on mission performance relative to costs—value that varies at each MHS level. 
At first glance, DMHRSi appears to be a tremendous value at the MHS enterprise level. Spending \$14 million annually (of a \$32.7 billion operations and maintenance budget), ${ }^{56}$ just $\$ 80$ per employee, on personnel visibility and management capabilities seems justified. ${ }^{57}$ However, DMHRS $i$ costs balloon to $\$ 570$ (plus five hours of primary duty time) per member when all costs are considered. ${ }^{58}$ By comparison, the average U.S. large business spends $\$ 860$ per employee per year on all HRM functions combined. ${ }^{59}$

The LCA module and MERHCF, however, make DMHRSi's value more compelling. While the LCA function incurs most of DMHRSi's indirect costs, it also allowed the MHS to eliminate systems, standardize LCA, and collect hundreds of millions of dollars in MERHCF reimbursements. ${ }^{60}$ Recapturing nearly $\$ 500$ per man-hour spent on LCA is an excellent return on investment for a general's time (\$170-per-hour composite pay rate), yet alone an E-1 (\$23 per hour). ${ }^{61}$ Still, LCA value must account for mission costs from lost productivity and staff dissatisfaction, which are difficult to quantify. For example, what are the aggregate costs of direct-care appointments lost to MTFs administering DMHRSi? The MHS pays 60 to 90 percent less for direct care than for the same care purchased in the civilian network. ${ }^{62}$ So, the MHS loses $\$ 300$ to $\$ 450$ for every $\$ 500$ appointment pushed to the network. This example still fails to account for costs related to care continuity, patient satisfaction, and worker absenteeism.

The above notwithstanding, DMHRSi is a very good value for DHA and the eMSMs. The benefits of integrated HRM data increase with organizational size and diversity (i.e., civilian, contractor, and Joint military mix). DHA and the eMSMs are the types of organizations DMHRS $i$ was designed to support—Joint MHS activities. These organizations not only enjoy the benefits of data aggregated from all five DMHRSi modules and pay relatively little for it; their missions depend on integrated data. DHA's role as the MHS governance body and its 
responsibilities to oversee shared services and improve readiness (while lowering the MHS' per capita costs) rely heavily on DMHRSi ${ }^{63}$ Further, authorities recently given to eMSM leaders fundamentally changed eMSM operations from mere coordination to integration across multiple Services and MTFs. ${ }^{64}$ Conducting this mission, as with DHA's, is unachievable without an integrated HRM system. According to the eMSM CONOPs, DMHRSi is " $[\mathrm{t}]$ he only...MHSwide data system currently capable of tracking the assignment of billets and personnel across a market." ${ }^{\prime 65}$ In the NCR eMSM - the MHS's largest with 37 MTFs, 13,000 personnel, and a \$1.2 billion budget—DMHRSi standardizes business practices, optimizes service and resource distribution, fosters education and training, and maintains "Joint information management solutions."66 With DMHRSi and recent policy changes, DHA and eMSM leaders now have the tools and authority for centralized control, unified effort, and success in a Joint operational environment. Shared-service savings of $\$ 3.5$ billion over the next five years and mission success enabled by DMHRSi make it a genuine value for DHA’s $\$ 14$ million annual investment. ${ }^{67}$

At the Service level, DMHRSi's value drops because these organizations are not Joint and they have other HRM systems that meet many of their needs, albeit in a Service-specific way. As a result, program managers assert the Services are using only a quarter of DMHRSi's capabilities. ${ }^{68}$ Said another way, the MHS is paying $\$ 40$ million for the system, but using just $\$ 10$ million worth of its capability...far from a great value. That's not to say DMHRS $i$ isn't valuable to the Services. Although Joint visibility is largely unnecessary, DMHRSi does give leaders at this level an integrated look at medical assets across MTFs—something difficult to piece together before DMHRSi. In reality, the value to each Service varies, as each is using a different mix of DMHRSi capabilities to support different missions and each is paying different costs. 
Among the medical departments, BUMED is extracting the best value from DMHRS $i$. They are currently the only branch employing all five of the system's modules, yet are paying similar costs. ${ }^{69}$ Assessing DMHRSi's relative value for the AFMS and AMEDD is challenging. Unlike BUMED, the AFMS and AMEDD are not using all DMHRSi modules. They instead rely on other systems to provide E\&T and readiness functions, a result of Service inertia or preference over DMHRS $i^{70}$ The DMHRSi LCA functions appear of equal value to all Services, as the MERHCF returns are proportional to the LCA-related costs. ${ }^{71}$

Finally, DMHRSi's value is arguably lowest at the MTF level since individual MTFs possess less staff diversity and are smaller than the higher levels. Typically, MTF leaders don't rely on DMHRSi data for decision-making or mission execution. ${ }^{72}$ MERHCF reimbursements are one of few consistent benefits for MTFs and some MTF leaders don't seem to understand this (despite receiving $\$ 500$ per man-hour). However, these leaders do know their people bear the bulk of DMHRSi's costs. ${ }^{73}$ Clear costs and unclear benefits mean the perceived value of DMHRS $i$ at the MTF level is lower than its actual value. Of course, the few MTFs that are employing more of DMHRSi's capabilities are getting a better value, i.e., the promise that "DMHRS $i$ will enable MTF Commanders to standardize and optimize the management of human capital by improving decision making., ${ }^{, 74}$

In the final analysis, DMHRSi's value is good overall and increases as you move up the MHS organizational structure. This is consistent with the business world's assertion that "HRM's main added value is situated in the strategic domain.,"75 DMHRSi's value also increases as more of its capabilities are employed, such as by BUMED and some MTFs, and varies by the type of capability employed. The LCA module has the highest costs of the three modules employed by all the Services and its value may be similar for the AFMS, AMEDD, and 
BUMED (if MERHCF returns are proportional to costs). Clearly, if the direct costs of DMHRSi were evenly divided by module, the E\&T and readiness modules would have the lowest value. So, with all that in mind, what should be done about it?

\section{$\underline{\text { Recommendations }}$}

Although DMHRS $i$ is a good value, there is room and need for improvement. Foremost, the MHS' share of DoD budget cuts (up to $\$ 22$ billion over the five years ending FY19) demands immediate and far-reaching actions. ${ }^{76}$ Toward that end, the FY15 Defense Health Program budget was reduced $\$ 695.4$ million compared to the previous year, ${ }^{77}$ the DHA is trying to save $\$ 3.5$ billion, and the MHS plans to cut 8 to 12 percent of its civilian workforce. ${ }^{78}$ Improving DMHRSi's value will not only contribute to the required savings, it might prevent additional manpower cuts. In light of the preceding analysis, DMHRSi's value to the MHS can be increased in two ways—expand the benefits and cut the costs—leading to four recommendations on how to proceed.

\section{Maximize Use of Existing DMHRSi Capabilities}

Using just 25 percent of a multimillion-dollar capability is clearly wasteful. Expanded DMHRS $i$ use to further standardize HRM will eventually be forced on the AFMS and AMEDD, therefore the program's value will increase over time. The MHS should aggressively engage these departments to adopt all DMHRSi capabilities as quickly as possible. This would have significant Joint advantages and address findings of the MHS report. Such standardization might also make medical service unification more attractive and economical. With MHS studies recommending a unified medical service, ${ }^{79}$ consolidation of MTFs and medical training, ${ }^{80}$ creation of DHA, and expansion of eMSM authorities, the 2006 DMHRSi CONOPs seems prescient in predicting "future usage policy will incorporate all DMHRSi modules to support a 
Joint Military Medical Command. ${ }^{, 81}$

Leaders at all levels must also look for innovative ways to integrate existing DMHRSi capabilities into their decision-making processes. For example, MTFs should incorporate the use of DMHRSi's integrated data into strategic plans, executive decision-making, and outputs to higher-level organizations. DHA should work with the contractor and the Services to address any unique HRM needs. Then, eMSMs will increasingly need to work with individual MTFs to expand and standardize their use of DMHRS $i$ capabilities to support the strategic decisions at both levels. Further, the Services should find new ways to leverage DMHRSi's underutilized capabilities, as the AFMS plans to do with manpower standards and AMEDD with face-to-space management.

In addition to these innovative efforts, the DMHRS $i$ E\&T and readiness functions should be analyzed to identify disconnects between the modules' capabilities and Service-specific requirements in order to eliminate system redundancies. The Services should also develop DMHRSi user guides or MTF best practices, and standardize these practices where possible. Finally, the MTFs must not only find more ways to incorporate available DMHRS $i$ capabilities into decision-making (like the MEPRS manager described earlier), they also need to support the system through continued advocacy and staff education. Beyond these efforts to use DMHRSi's existing capabilities, expanding the system's capabilities will also increase its value.

\section{Improve DMHRSi Capabilities}

DMHRS $i$ is a capable program; still, several enhancements could improve its capabilities and, consequently, its value. As mentioned, the E\&T and readiness modules may require modifications to meet Service and MTF needs. Additionally, a transparent interface with ATAAPS should be created, which would reduce the costs of duplicative effort, dissatisfaction, 
and rejected timecards from civilian employees. Development of an automated DMHRSi error check would further reduce the time spent on rejected timecards. For example, mistakes such as entering excess duty time could be automatically flagged as potential errors for the user to address before timecard submission. A LeaveWeb interface to automatically populate leave data in DMHRS $i$ would further decrease rejections and improve data accuracy. Lastly, the capability to import contract employee data would save the time currently required for manual entry.

Beyond these software enhancements, two additional DMHRS $i$ improvements must be considered. First, augmenting the system's report capability is essential. A solution to the report deficiencies—-the DMHRSi Data Repository—has been promised, but implementation has been delayed several times. These delays have led some organizations to create inefficient workarounds and others to limit the use of DMHRSi altogether, contributing to low utilization rates. The Data Repository (and its enhanced reporting capability) also has the potential to reduce the Services' needs for expensive support contracts and would increase the value to MTF leaders. This solution's roll-out should be fast-tracked. Second, centralized system support should be expanded by broadening the MHS-level contract. Generally, consolidated contracts are more cost effective than separate contracts for the same service, even just by eliminating redundant overhead. An expansion of the MHS contract and increased MTF capability should reduce the costs of DMHRS $i$ and improve its value, as should the next two recommendations.

\section{Eliminate Redundant Capabilities}

DMHRS $i$ "eliminates the need for stand-alone systems with redundant databases." 82 However, this benefit has not been realized beyond just a few retired legacy LCA programs. Leaders at all levels must make a concerted effort to evaluate their existing HRM systems and eliminate those that add little beyond DMHRSi. Presently, DMHRSi interfaces with 23 systems, 
and they are a good place to start identifying redundancies. ${ }^{83}$ Adopting DMHRSi for some functions may entail accepting decreased capabilities or practice changes in the short-term while DMHRS $i$ is refined.

The AFMS DMHRS $i$ CONOPs, for example, says "the readiness and E\&T modules of DMHRSi will not be used." 84 While DMHRS $i$ may not currently provide the same E\&T and readiness functions as the Medical Readiness Decision Support System, the AFMS needs to work with DHA to incorporate the functions it needs. Similarly, MHS Learn and DMHRSi E\&T share a similar vision as a "one-stop shop" for medical education and training, but the DMHRS $i$ capability is largely unused. At the MTF level, leaders should evaluate local HRM systems and solutions (such as homegrown Excel spreadsheets) for redundancies with DMHRSi capabilities. Considering the limited use and familiarity of DMHRSi at this level, this evaluation will likely benefit the MTF. The MHS Quadruple Aim demands we lower costs by creating value in "eliminating waste and reducing unwarranted variation." 85 A thorough review of our HRM systems and the elimination of redundant capabilities will do just that.

\section{Reduce LCA Costs}

Finally, LCA — the costliest function of DMHRSi — must be thoroughly evaluated for potential savings. MERHCF is clearly important to the MHS, but capturing this funding is achievable at lower cost. The greatest cost reduction would be realized by changing the way MERHCF reimbursements are calculated to eliminate the need for LCA altogether. A change from the current fee-for-service (tally of individual costs) approach to episode-of-care (preestablished cost bundles) billing, similar to Medicare's payment model, would make the laborintensive LCA process unnecessary. In fact, a government think-tank recommended this approach when MERHCF was established. ${ }^{86}$ They advised using level-of-effort calculations for 
the first few years, then "recommend that withdrawal calculations use variations of current thirdparty collection rates that are now used to charge other agencies and civilian health insurers for beneficiaries' care." 87 The Services' concerns about the potential for reimbursements to be lower than actual expenses could be mitigated. For example, a combination of MEPRS non-labor expenses plus standard labor reimbursement rates might be a solution, especially since labor costs are comparable among MTFs. This methodology would not only eliminate the substantial costs of LCA, it would eliminate the LCA data-accuracy problem that leads to miscalculations of “actual" costs.

There are other ways to reduce the LCA costs in the near-term. One option is to require timecard completion by exception, whereby only employees with unstable work schedules would document deviations. Many MHS employees divide their duty time in a consistent pattern and day-to-day variations are insignificant to annual MERHCF reimbursements, so standard timecards with changes by exception would provide reasonably accurate LCA data at lower cost. Other options to reduce LCA costs include using surrogate data (e.g., CHCS workload data), requiring timecards only from select staff, and further automation of timecards (e.g., interface with Outlook calendars). If CHCS workload has a 92 percent correlation to LCA data, as indicated by DHA, provider timecards are not adding much value.

Probably the least effective way to reduce LCA costs, although attractive on the surface, is to better educate the MTF staff on timecard importance. In reality, education can only do so much. Although MTFs receive a significant amount of funding through MERHCF, the connection is not clear, nor of concern, to the average employee. The costs are borne at their level, while the benefits are most evident at the higher levels. Even if education could clear this hurdle, it will not reduce the significant costs associated with time, salaries, and opportunity. 
While each of the recommendations above can stand on its own, they need to be considered collectively as the MHS moves forward. Actions to both increase the benefits and decrease the costs of this system are necessary. These actions must not be evaluated in isolation, but as a comprehensive approach to improving value. As Michael Porter, the noted economist, asserted about healthcare value, "Cost reduction without regard to the outcomes achieved is dangerous and self-defeating, leading to false "savings." 88 DMHRS $i$ cost savings must be similarly evaluated against the benefits the system offers the MHS.

\section{$\underline{\text { Conclusion }}$}

DMHRSi benefits the MHS in many ways through the integration and visibility of mission-critical HRM data. To achieve these benefits, the MHS and its personnel pay significant direct and indirect costs. Despite these costs, DMHRS $i$ is a relatively good value to the MHS. However, the MHS is challenged by significant budget pressure and personnel reductions, while at the same time radically changing its governance structure and shifting its strategic direction toward increasing Joint medical operations. As a result, the MHS must find ways to increase the value of DMHRSi even more. Effective management of DoD's most important resource, its people, and the resulting mission success depend on it. 


\section{$\underline{\text { Appendix A: Cost Calculations }}$}

1. BUMED DMHRSi Managers: GS-14, Step 1 salary ("Rest of US," position located in Jacksonville, FL) = \$97,657; GS-12, Step 1 salary (“Rest of US”) =\$69,497 x $4=\$ 277,988$; $\$ 97,657+\$ 277,988=\$ 375,645$

2. AFMOA MEPRS Manager: GS-12, Step 1 salary ("Rest of US," position located in San Antonio, TX) $=\$ 69,497 \times 0.33($ percent of time dedicated to DMHRSi) $=\mathbf{\$ 2 2 , 9 3 4}$

3. AMEDD DMHRSi Manager: GS-13, Step 1 salary ("DC-MD-VA," position located in Falls Church, VA) $=\$ 89,924 \times 1$ (percent of time dedicated to DMHRSi) $=\mathbf{\$ 8 9 , 9 2 4}$

4. $\underline{\text { MTF MEPRS Managers: }}$ GS-9, Step 1 salary (Rest of US)* $=\$ 47,923$ x 0.75 (percent of time dedicated to DMHRSi $)=\$ 35,942 \times 650(\text { sites })^{* *}=\mathbf{\$ 2 3 , 3 6 2 , 4 6 2}$

*Rather than attempting to account for variations in grade, step level, and locality pay adjustments, a best-case (i.e., lowest cost) estimate is used here.

**Actual number of sites and MTF MEPRS Managers per site may vary, as requirements are different based on type of MEPRS site ("parent" vs. "child”), MTF size, and other local factors. This estimate assumes one MEPRS Manager per site and 650 total sites.

5. MHS Personnel (Indirect Costs): 170,000 (DMHRSi users) x 10 (minutes per timecard) x 26 (timecards per year) $=736,666$ hours per year; 4,800 (minutes per pay period, assuming standard 40-hour work week) $/ 10$ (minutes per timecard) $=0.2 \%$ (portion of time dedicated to timecard completion); $\$ 27.2$ billion (pay and benefits for MHS personnel) $\times 0.2 \%=$

\section{$\$ 54,400,000$}




\section{$\underline{\text { Appendix A: Cost Calculations (cont'd) }}$}

6. MTF Timekeepers: 170,000 (DMHRS $i$ users) / 30 (users per timekeeper) $=5,666$ (timekeepers) x 30 (minutes per time period) x 26 (time periods) $=$ 73,666 (hours per year) $/ 8$ (hours per day) = 9,208 (man-days); \$65,771 (annual composite pay rate for E-4* (Army, Air Force, and Navy average $) \times 0.00439$ (conversion for daily rate, as provided in reference $)=$ $\$ 288.74$ (per E-4 man-day) x 9,208 (man-days per year) $=\mathbf{\$ 2 , 6 5 6 , 3 7 3}$ (per year)

*MTF timekeepers are typically in the grades of E-4 through E-6. Rather than attempting to account for variations in grade, time in service, special pays, and other variations, this estimate conservatively assumes all timekeepers are E-4s receiving the composite pay rate.

7. DMHRSi Cost Per Employee: $\$ 14$ million (software cost) / 170,000 (users) $=\mathbf{\$ 8 2 . 3 5} ; \$ 40$ million $($ direct costs) $/ 170,000$ (users) $=\mathbf{\$ 2 6 5 . 2 9} ; \$ 97$ million $($ direct $\&$ indirect costs) $/$ 170,000 (users) $=\$ \mathbf{5 7 0 . 5 9}$

8. LCA Recapture Rate: $\$ 500$ million (MERHCF reimbursement) - \$97 million (DMHRSi direct and indirect costs) / 812,000 (man-hour costs) $=\$ \mathbf{4 9 6}$ (reimbursement per man-hour) 


\section{$\underline{\text { Notes }}$}

(All notes appear in shortened form. For full details, see the proper entry in the bibliography)

1. Hopper, Interview.

2. Office of the Secretary of Defense (OSD), "Estimated Impacts of Sequestration-Level Funding," Chapter 1.

3. Kabene et al., "The Importance of Human Resources Management in Health Care: A Global Context," 1478.

4. OSD. "Human Resources Management: Strategic Plan, Fiscal Years 2012 - 2016," 3.

5. OSD. "Human Resources Management: Strategic Plan, Fiscal Years 2012 - 2016," 9-10.

6. OSD. "Human Resources Management: Strategic Plan, Fiscal Years 2012 - 2016," 9-10.

7. Office of the Assistant Secretary of Defense (Health Affairs) [OASD(HA)], Joint DMHRSi CONOPS, 6.

8. Hopper, interview.

9. OASD(HA), Joint DMHRSi CONOPS, 17; and Hopper, interview.

10. TRICARE Management Activity (TMA), "Human Capital Information \& The Defense Medical Human Resources System - internet (DMHRSi)," 5.

11. TMA, "Data Integrity Breakouts (Navy) MEPRS - 100\% DMHRSi Requirement," 6.

12. OASD(HA), Joint DMHRSi CONOPS, 8-49.

13. TMA, "Data Integrity Breakouts (Navy) MEPRS - 100\% DMHRSi Requirement," 10.

14. DoD Directive 6000.12E, Health Services Support, 3.

15. AFMS, DMHRSi AFMS CONOPS, 28.

16. OASD(HA), Joint DMHRSi CONOPS, 15.

17. Deputy SecDef, Implementation of Military Health System Governance Reform.

18. Hopper, interview; and Robb, "Military Health System: MHS Transformation;" DHA shared services include: facilities, medical logistics, health information technology, TRICARE health plan, pharmacy programs, budget $\&$ resource management, procurement/contracting, research/development/acquisitions, medical education \& training, and public health.

19. Hopper, interview.

20. Richwine, interview.

21. Richwine, interview.

22. Andre, interview.

23. Andre, interview. 
24. Andre, interview.

25. OASD(HA), Joint DMHRSi CONOPS, 9; and AFMS, DMHRSi AFMS CONOPS, 4.

26. Coventry, "MEPRS: What It's Good For," 30-1.

27. Hopper, interview.

28. Kearny \& Company, "Fiscal Year 2013 Medicare-Eligible Retiree Health Care Fund Audited Financial Statements," 12.

29. Andre, interview.

30. Coventry, "MEPRS: What It's Good For," 34-5.

31. TMA,"Human Capital Information \& The Defense Medical Human Resources Systeminternet (DMHRSi)," 7-8.

32. Interviews with MTF MEPRS managers, 31 Oct 2014, 5 Nov 2014, 18 Nov 2014, and 21 Jan 2015.

33. Interview with MTF MEPRS manager, 31 Oct 2014.

34. Graser, The Economics of Air Force Medical Service Readiness, 37-44.

35. Graser, The Economics of Air Force Medical Service Readiness, 27-37.

36. Hopper, Interview.

37. Stewart, Interview; and Office of Personnel Management, "Salary Table 2014-RUS." See Appendix A, cost calculation 1.

38. Andre, Interview; Richwine, Interview; Office of Personnel Management, "Salary Table 2014-RUS;" and Office of Personnel Management, "Salary Table 2014-DCB." See Appendix A, cost calculations 2 and 3 .

39. Interviews with MTF MEPRS managers, 31 Oct 2014, 5 Nov 2014, 18 Nov 2014, and 21 Jan 2015. Specific tasks include ensuring $100 \%$ of timecards are submitted, performing quality control of timecards, reconciling reports, and submitting data to headquarters.

40. DoD, "Overview of the Department of Defense's Military Health System"; and Office of Personnel Management, "Salary Table 2014-RUS." See Appendix A, cost calculation 4.

41. DoD Manual 6010.13-M, Medical Expense and Performance Reporting System for Fixed Military Medical and Dental Treatment Facilities Manual, 182; and AFI 41-102, Medical Expense and Performance Reporting System (MEPRS) for Fixed Military Medical and Dental Treatment Facilities,9.

42. Graser, The Economics of Air Force Medical Service Readiness, 36.

43. Hopper, Interview.

44. Interviews with MTF MEPRS managers, 31 Oct 2014, 5 Nov 2014, 18 Nov 2014, and 21 Jan 2015. 
45. Interviews with MTF MEPRS managers, 31 Oct 2014, 5 Nov 2014, 18 Nov 2014, and 21 Jan 2015.

46. Defense Health Services Systems. "DMHRSi Fact Sheet"; and Congressional Budget Office, Approaches to Reducing Federal Spending on Military Health Care, 5-6. See Appendix A, cost calculation 5 .

47. Interviews with MTF MEPRS managers, 31 Oct 2014, 5 Nov 2014, 18 Nov 2014, and 21 Jan 2015.

48. OUSD(C), "FY 2015 Department of Defense (DoD) Military Personnel Composite Standard Pay and Reimbursement Rates." See Appendix A, cost calculation 6.

49. DoD Manual 6010.13-M, Medical Expense and Performance Reporting System for Fixed Military Medical and Dental Treatment Facilities Manual, 182.

50. Loftus, Memorandum, DMHRSi Labor Cost Timesheet 100 Percent Compliance.

51. TMA, "Defense Medical Human Resource System internet (DMHRSi) Beyond Timesheets," 6.

52. Andre, Interview; Richwine, Interview; and Stewart, Interview.

53. Interviews with MTF MEPRS managers, 31 Oct 2014, 5 Nov 2014, 18 Nov 2014, and 21 Jan 2015.

54. Porter, "What is Value in Health Care," 2477.

55. TMA, "Achieving the Quadruple Aim: Focusing on Strategic Imperatives," 2-17.

56. OUSD(C), "Defense Health Program Fiscal Year (FY) 2015 Budget Estimates."

57. See Appendix A, cost calculation 7.

58. See Appendix A, cost calculation 7.

59. Bureau of National Affairs, Inc., HR Department Benchmarks and Analysis, xiii.

60. Hopper, Interview; and Andre, Interview.

61. OUSD(C), "FY 2015 Department of Defense (DoD) Military Personnel Composite Standard Pay and Reimbursement Rates." See Appendix A, cost calculation 8.

62. Kokulis, "Preserving the Military Health Care Benefit," 7.

63. OSD, "Human Resources Management: Strategic Plan, Fiscal Years 2012 - 2016,"

64. DoD, Enhanced Multi-Service Market Concept of Operations, 2-3.

65. DoD, Enhanced Multi-Service Market Concept of Operations, 38.

66. National Capital Region Medical Directorate, website.

67. Robb, "Military Health System: MHS Transformation," 22.

68. Hopper, Interview; Andre, Interview; Richwine, Interview; and Stewart, Interview. 
69. OASD(HA), Joint DMHRSi CONOPS, 17-22; Andre, Interview; Richwine, Interview; and Stewart, Interview.

70. Andre, Interview; and Richwine, Interview.

71. A full assessment of MEPRS would be required for a more comprehensive evaluation of LCA value to the three Services.

72. Interviews with MTF MEPRS managers, 31 Oct 2014, 5 Nov 2014, 18 Nov 2014, and 21 Jan 2015.

73. Interviews with MTF MEPRS managers, 31 Oct 2014, 5 Nov 2014, 18 Nov 2014, and 21 Jan 2015.

74. OASD(HA), Joint DMHRSi CONOPS, 23.

75. Buyens and Verbrigghe, "Adding Value and HRM Practice: Evidence Based HR," 17.

76. DHA, "Pharmacy Operations Overview," 31 October 2013.

77. OUSD(C), "Defense Health Program Fiscal Year (FY) 2015 Budget Estimates."

78. OSD, "Defense Budget Priorities and Choices: Fiscal Year 2014," 3-4.

79. Robb, "Military Health System: MHS Transformation," 10.

80. Towell and Belasco, Defense: FY2014 Authorization and Appropriations, 23-5.

81. OASD(HA), Joint DMHRSi CONOPS, 15.

82. AFMS, DMHRSi AFMS CONOPS, 6.

83. TMA, "Human Capital Information \& The Defense Medical Human Resources System internet (DMHRSi)," 5.

84. AFMS, DMHRSi AFMS CONOPS, 6.

85. TMA, "Achieving the Quadruple Aim: Focusing on Strategic Imperatives," 2.

86. Etheridge, et al., Accrual Funding for Military Retirement Health Care, iv.

87. Etheridge, et al., Accrual Funding for Military Retirement Health Care, iv.

88. Porter, "What is Value in Health Care," 2477. 


\section{Bibliography}

Air Force Instruction (AFI) 41-102. Medical Expense and Performance Reporting System (MEPRS) for Fixed Military Medical and Dental Treatment Facilities, 9 May 2014.

Air Force Medical Service, Defense Medical Human Resources System-internet Air Force Medical Services Concept of Operations, Version 3.2, 11 April 2011.

Andre, Keith (Air Force Medical Operations Agency, MEPRS Program Manager). Interview by the author, 13 November 2014.

Bureau of National Affairs, Inc. HR Department Benchmarks and Analysis, 2014-2015, http://www.bna.com/uploadedFiles/Content/Products/Human_Resources/Reports/Executive\% 20Summary\%20and\%20TOC\%20HR\%20Benchmarks\%202015.pdf (accessed 7 December 2014).

Buyens, Dirk, and Jasmijn Verbrigghe. "Adding Value and HRM Practice: Evidence Based HR," in Human Resource Management Practices, ed. Maike Andresen and Christian Nowak (Switzerland: Springer International Publishing, 2015).

Congressional Budget Office. Approaches to Reducing Federal Spending on Military Health Care, January 2014.

Coventry, John A. SRA International, Inc., “MEPRS: What It's Good For,” 29 July 2010.

Defense Health Agency. "Pharmacy Operations Overview," 31 October 2013, https://kx2.afms. $\mathrm{mil} / \mathrm{kj} / \mathrm{kx} 2 / \mathrm{Pharmacy} /$ Documents/Forms/ShowFolders.aspx?RootFolder=\%2fkj\%2fkx $2 \% 2 \mathrm{fPh}$ armacy\%2fDocuments\%2fLeadership\&FolderCTID=0x012000CCD2703692D2F242BD1AE 5FBAFA3621F (accessed 22 September 2014).

Defense Health Services Systems. "DMHRSi Fact Sheet," October 2013.

Department of Defense. Enhanced Multi-Service Market Concept of Operations, 11 April 2014.

Department of Defense. "Overview of the Department of Defense's Military Health System," June 2014, http://www.defense.gov/home/features/2014/0614_healthreview/docs/Fact_Sheet_ Overview. PDF (accessed 18 January 2015).

Department of Defense Directive 6000.12E. Health Services Support, 6 January 2011.

Department of Defense Manual 6010.13-M. Medical Expense and Performance Reporting System for Fixed Military Medical and Dental Treatment Facilities Manual, 7 April 2008 (Incorporating Change 2, effective 15 April 2014).

Deputy Secretary of Defense. Policy memorandum, Implementation of Military Health System Governance Reform, 11 March 2013.

Etheridge, Melvin R. Jr., Bobby Jackson, Howard L. Hiller, and William T. Gray. Accrual Funding for Military Retirement Health Care. PR008R1. McLean, VA: Logistics Management Institute, January 2001.

Graser, John C., et al. The Economics of Air Force Medical Service Readiness. RAND Report FA7014-06-C-0001. Santa Monica, CA: RAND, 2010. 
Hopper, Mike (Defense Health Agency, Manpower and Organization Division Chief). Interview by the author, 8 September 2014.

Kabene, Stefane M., et al. "The Importance of Human Resources Management in Health Care: A Global Context.” Human Resources for Health 2006, 4:20 (27 July 2006).

Kearney \& Company. Fiscal Year 2013 Medicare-Eligible Retiree Health Care Fund Audited Financial Statements, December 2013.

Kokulis, John L., American Enterprise Institute. "Preserving the Military Health Care Benefit: Needed Steps for Reform," October 2013, http://www.aei.org/publication/preserving-themilitary-health-care-benefit-needed-steps-for-reform/ (accessed 21 January 2015).

Loftus, Maj Gen Thomas J., Air Force Assistant Surgeon General for Health Care Operations (HQ USAF/SG3). To ALMAJCOM/SG. Memorandum, Subject: Defense Medical Human Resource System Internet (DMHRSi) Labor Cost Timesheet 100 Percent Compliance, 19 November 2009.

Medical Treatment Facility (MTF) Medical Expense and Performance Reporting System (MEPRS) Managers. Interviews by the author, 31 October 2014, 5 November 2014, 18 November 2014, and 21 January 2015. All interviews were conducted in confidentiality, and the names of interviewees are withheld by mutual agreement.

National Capital Region Medical Directorate. http://www.capmed.mil/About/SitePages/About .aspx (accessed 10 December 2014).

Office of Personnel Management, "Salary Table 2014-RUS Incorporating the 1\% General Schedule Increase and a Locality Payment of 14.16\% for the Locality Pay Area of Rest of U.S.,"January 2014, http://www.opm.gov/policy-data-oversight/pay-leave/salarieswages/salary-tables/pdf/2014/RUS.pdf (accessed 22 September 2014).

Office of the Assistant Secretary of Defense for Health Affairs. Joint Concept of Operations for the Defense Medical Human Resources System-internet, July 2006.

Office of the Secretary of Defense. "Defense Budget Priorities and Choices: Fiscal Year 2014," April 2013, http://www.defense.gov/pubs/DefenseBudgetPrioritiesChoicesFiscalYear 2014.pdf (accessed 22 September 2014).

Office of the Secretary of Defense. "Estimated Impacts of Sequestration-Level Funding," April 2014, http://www.defense.gov/pubs/2014_Estimated_Impacts_of_Sequestration-

Level_Funding_April.pdf (accessed 28 November 2014).

Office of the Secretary of Defense. "Human Resources Management: Strategic Plan, Fiscal Years 2012 - 2016," 29 March 2013, http://www.prim.osd.mil/Documents/HRM_ StrategicPlan_29Mar13_Final.pdf (accessed 8 November 2014).

Office of the Undersecretary of Defense (Comptroller). "Defense Health Program Fiscal Year (FY) 2015 Budget Estimates Defense Health Program Appropriation Highlights," Exhibit PBA-19, http://comptroller.defense.gov/Portals/45/Documents/defbudget/fy2015/budget_ justification/pdfs/09_Defense_Health_Program/VOL_I_Sec_1_PBA-19_Introductory_ Statement_DHP_PB15.pdf (accessed 2 October 2014). 
Office of the Undersecretary of Defense (Comptroller). "FY 2015 Department of Defense (DoD) Military Personnel Composite Standard Pay and Reimbursement Rates," http://comptroller. defense.gov/Portals/45/documents/rates/fy2015/2015_k.pdf (accessed 30 November 2014).

Porter, Michael E. "What is Value in Health Care?," The New England Journal of Medicine 363, no. 26 (23 December 2010): 2477-81.

Richwine, Joan M. (Office of the Surgeon General of the Army, Human Resources, DMHRS $i$ Systems Analyst). Interview by the author, 4 December 2014.

Robb, Lt Gen Douglas J. “Military Health System: MHS Transformation” (lecture, Air War College, Maxwell AFB, AL, 8 October 2014).

Stewart, Michael L. (Navy Bureau of Medicine and Surgery, DMHRSi Program Manager). Interview by the author, 30 January 2015.

Towell, Pat, and Amt Belasco. Defense: FY 2014 Authorizations and Appropriations. Washington, D.C.: Congressional Research Service, 8 January 2014.

TRICARE Management Activity. "Achieving the Quadruple Aim: Focusing on Strategic Imperatives,” 24 January 2011, http://www.dtic.mil/dtic/tr/fulltext/u2/a556276.pdf (accessed 7 December 2014).

TRICARE Management Activity, Office of the Chief Financial Officer. "Defense Medical Human Resource System internet (DMHRSi) Beyond Timesheets," September 2010, http://www.tricare.mil/ocfo/_docs/Stewart\% (accessed 2 October 2014).

TRICARE Management Activity, Office of the Chief Information Officer. "Human Capital Information \& The Defense Medical Human Resources System - internet (DMHRSi)," September 2012, http://www.tricare.mil/ocfo/_docs/Redacted_W-3_HOPPER_DMHRSi_ Beyond_Timesheets.ppt (accessed 18 November 2014).

TRICARE Management Activity, Uniform Business Office. "Data Integrity Breakouts (Navy) MEPRS - 100\% DMHRSi Requirement" (presentation, 2011 MHS Revenue Cycle Educational Conference), http://www.tricare.mil/ocfo/_docs/2011_R-4-1440\%20 MEPRS\%20-\%20DMHRSi_redacted.pptx (accessed 22 September 2014). 